\title{
Activin A/BMP2 Chimera (AB204) Exhibits Better Spinal Bone Fusion Properties than rhBMP2
}

\author{
Dalsung Ryu, M.D., ${ }^{1}$ Byung-Hak Yoon, Ph.D., ${ }^{2}$ Chang-Hyun Oh, M.D., Ph.D., ${ }^{1,3}$ Moon-Hang Kim, Ph.D., Ji-Yong Kim, M.D., \\ Seung Hwan Yoon, M.D., Ph.D., ${ }^{1}$ Senyon Choe, Ph.D. ${ }^{2,5}$ \\ Department of Neurosurgery, Inha University College of Medicine, Incheon, Korea \\ Protein Engineering Laboratory, joint Center for Biosciences at Songdo Global University, Incheon, Korea \\ Department of Neurosurgery, ${ }^{3}$ Cham Teun Teun Research Institute, Seoul, Korea \\ Department of Physiology, ${ }^{4}$ Inha University College of Medicine, Incheon, Korea \\ Structural Biology Laboratory, ${ }^{5}$ The Salk Institute for Biological Studies, La Jolla, CA, USA
}

Objective : To compare the spinal bone fusion properties of activin A/BMP2 chimera (AB204) with recombinant human bone morphogenetic protein (rhBMP2) using a rat posterolateral spinal fusion model.

Methods : The study was designed to compare the effects and property at different dosages of AB204 and rhBMP2 on spinal bone fusion. Sixty-one male Sprague-Dawley rats underwent posterolateral lumbar spinal fusion using one of nine treatments during the study, that is, sham; osteon only; $3.0 \mu \mathrm{g}, 6.0 \mu \mathrm{g}$, or $10.0 \mu \mathrm{g}$ of rhBMP2 with osteon; and $1.0 \mu \mathrm{g}, 3.0 \mu \mathrm{g}, 6.0 \mu \mathrm{g}$, or $10.0 \mu \mathrm{g}$ of AB204 with osteon. The effects and property on spinal bone fusion was calculated at 4 and 8 weeks after treatment using the scores of physical palpation, simple radiograph, micro-computed tomography, and immunohistochemistry.

Results : Bone fusion scores were significantly higher for $10.0 \mu \mathrm{g} \mathrm{AB204}$ and $10.0 \mu \mathrm{g}$ rhBMP2 than for osteon only or $1.0 \mu \mathrm{g}$ AB204. AB204 exhibited more prolonged osteoblastic activity than rhBMP2. Bone fusion properties of AB204 were similar with the properties of rhBMP2 at doses of 6.0 and $10.0 \mu \mathrm{g}$, but, the properties of AB204 at doses of $3.0 \mu \mathrm{g}$ exhibited better than the properties of rhBMP2 at doses of $3.0 \mu \mathrm{g}$.

Conclusion : AB204 chimeras could to be more potent for treating spinal bone fusion than rhBMP2 substitutes with increased osteoblastic activity for over a longer period.

Key Words : Spinal fusion · Activin A · Bone morphogenetic proteins · Fusion · Rat.

\section{INTRODUCTION}

In spinal surgery, using bone substitutes has been increased world-widely with the reports about bone grafting as the second most frequent type of tissue transplantation ${ }^{3,5}$. Bone sub- stitute was defined as any synthetic, inorganic, or biologic organic combination, other than autogenous or allogenous bone, that can be inserted to treat bone defects ${ }^{25}$. An ideal bone substitute should be biocompatible, not evoke any adverse inflammatory response, be easily molded into bone de-

- Received : November 27, 2017 •Revised : December 25, 2017 •Accepted : February 20, 2018

- Address for reprints : Seung Hwan Yoon, M.D., Ph.D.

Department of Neurosurgery, Inha University College of Medicine, 27 Inhang-ro, Jung-gu, Incheon 22332, Korea

Tel : +82-32-890-2370, Fax : +82-32-890-2374, E-mail : nsyoon@gmail.com

This is an Open Access article distributed under the terms of the Creative Commons Attribution Non-Commercial License (http://creativecommons.org/licenses/by-nc/4.0) which permits unrestricted non-commercial use, distribution, and reproduction in any medium, provided the original work is properly cited. 
fects, have a short setting time, and be osteoconductive, osteoinductive, resorbable, radiographically checkable, thermally nonconductive, sterilizable, readily available, and reasonably priced $^{5,19,24)}$. While many bone substitutes have been introduced, recombinant bone morphogenetic protein 2 (rhBMP2) is most commonly used to enhance bone fusion after spinal fusion $^{18,23)}$. However, high doses of rhBMP2 are frequently required to achieve therapeutic effects, and it can induce undesirable side effects, such as, abnormal soft tissue swelling, dysphagia, heterotopic bone formation, cyst-like bone formation, cancer, and transient postoperative renal insufficiency ${ }^{12,15)}$. Hence, bone morphogenetic protein 2 (BMP2) substitutes which qualifying higher therapeutic potency and fewer side effects are studied and experimented.

Recently, the novel activin A/BMP2 (AB2) chimera, AB204, was shown to more potently and effectively promote osteogenesis and bone healing than $\operatorname{rhBMP} 2^{1,29)}$. In fact, one of these studies provided in vitro and in vivo evidence that treatment with AB204 completely healed critically sized tibial and calvarial defects in mice at concentrations 10-fold lower than that required for rhBMP $2^{29)}$. According to in vitro signaling assays, AB204 shares and shows greater activity at the same signaling receptors and Smads as $\mathrm{rhBMP} 2^{1)}$. Reportedly, AB204 is not sensitive to the BMP2 antagonist Noggin, and its affinity for activin/BMP type II receptor ActRII is 100-fold greater than that of rhBMP2 $2^{29)}$. Furthermore, structure-guided mutagenesis (AB204 I103Y mutant) significantly increased in the affinity of AB204 for its type I receptor BMPRIa and further enhanced the osteogenic potency of AB204 ${ }^{29)}$. These results suggest that $\mathrm{AB} 204$ at lower dosages can achieve the same treatment effects as rhBMP2, and with fewer unwanted side effects. Moreover, assuming the same diffusion and degradation rates for $\mathrm{rhBMP} 2$ and $\mathrm{AB} 204$, we suspected that a smaller amount of AB204 might be needed to achieve the

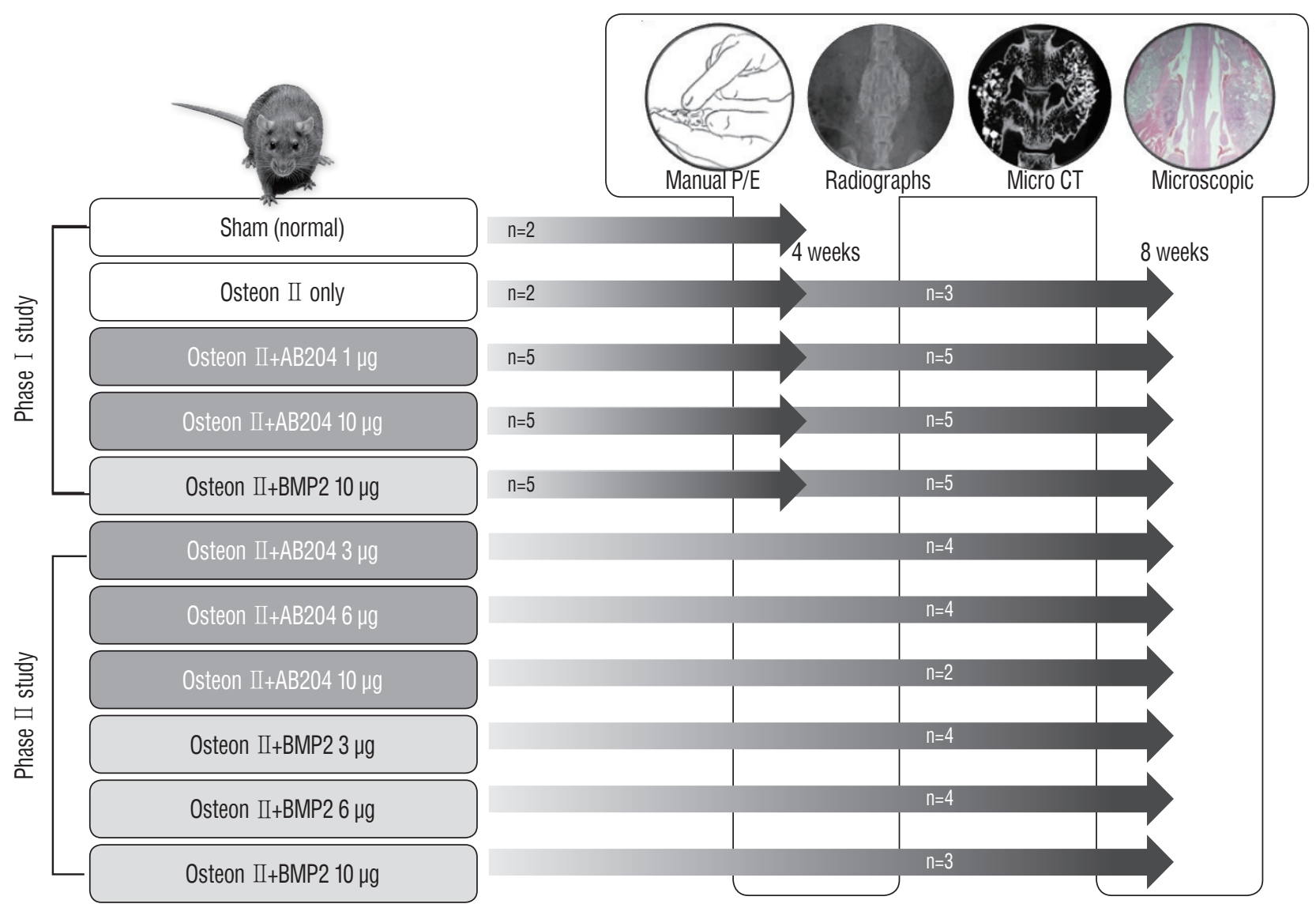

Fig. 1. Study design to compare the effects of AB204 chimera and rhBMP2 on spinal bone fusion and to evaluate spinal bone fusion properties according to dose. P/E : physical examination, CT : computed tomography, AB204 : activin A/BMP2 chimera, rhBMP2 : recombinant human bone morphogenetic protein. 
same therapeutic effects as rhBMP2. The smaller doses should have less negative impact on sites of administration and be less toxic to osteoblasts, as AB204 is cleared from the circulation faster than rhBMP2 $2^{29)}$. Accordingly, this study was conducted to evaluate and compare the spinal bone fusion properties of AB204 and rhBMP2 in a rat spinal fusion model.

\section{MATERIALS AND METHODS}

Procedures were performed at the Animal Research Laboratory in Inha University and approved by Inha University's Animal Care Committee (HI14C0797). Fifty-eight of 8-weekold male (Sprague-Dawley) rats (weight, 270-290 g) were used, and this study was conducted in two phases; first phase was designed to demonstrate the effects of AB204 (1.0 $\mu \mathrm{g}$ and $10.0 \mu \mathrm{g})$ and rhBMP2 $(10.0 \mu \mathrm{g})$ on spinal bone fusion comparing with control group, and the second phase was performed to assess and compare the spinal bone fusion properties of AB204 and rhBMP2 depending on different dosages (1.0, 3.0, 6.0, or $10.0 \mu \mathrm{g}$ ). Animals were allocated to one of nine treatment groups, as follows; sham (controls) (group 1); osteon only, as a scaffold insertion (group 2); $3.0 \mu \mathrm{g}$ (group 3), $6.0 \mu \mathrm{g}$ (group 4); or $10.0 \mu \mathrm{g}$ (group 5) dose of rhBMP2 with osteon; and $1.0 \mu \mathrm{g}$ (group 6); $3.0 \mu \mathrm{g}$ (group 7); $6.0 \mu \mathrm{g}$ (group 8); or 10.0 $\mu \mathrm{g}$ (group 9) dose of AB204 with osteon (Fig. 1).

AB204 was expressed in Escherichia coli, and chemically refolded $^{29)}$. After purification by heparin affinity and C4 reverse phase chromatography, the refolded protein was lyophilized for storage. The materials of AB204 and rhBMP2 were prepared from by joint Protein Central (Incheon, Korea). Before use, the lyophilized proteins were reconstituted in $1 \mathrm{mM}$ hydrochloric acid and then diluted by at least a factor of 100 in the appropriate final buffer or media including phosphatebuffered saline. The prepared AB204 chimera was positioned at the posterolateral lumbar vertebrae of rats using osteon (acting as scaffold).

All animal procedures were conducted according to the guidelines issued on animal experimentation at our institute. Rats were sedated with $20 \mathrm{mg} / \mathrm{kg}$ of Zoletil 50 i.p. (Virbac, S.A, Carros, France) and $10 \mathrm{mg} / \mathrm{kg}$ of Rompun $2 \%$ solution intraperitoneal (Bayer, Leverkusen, Germany) before surgery. The surgical procedure followed as previously described ${ }^{13,28)}$. A posterior midline skin incision followed by two separate para- median incisions at the lumbar fascia $3 \mathrm{~mm}$ from the midline to expose transverse processes (Fig. 2). Transverse processes of L4 and L5 were decorticated using a low-speed burr, and the scheduled bone fusion material was then implanted on both sides. Rats were housed in separate cages, allowed to eat and drink adequately, and their daily conditions were monitored.

Spinal bone fusion in rat models were checked at 4 and 8 weeks in first study phase or 8 weeks in second study phase after treatment. Spinal bone fusion was quantified by several methods such as physical palpation, simple radiography, micro-computed tomography (CT), and immunohistochemistry after sacrificing. For each examination, results were manually scored as no fusion (0), partial fusion (1), or complete fusion (2), and total sum scores were used to compare the fusion scores (Fig. 3) ${ }^{11)}$. Lumbar spines of rats were manually tested for intersegmental motion and the presence of any motion on either side (facets or transverse processes) was considered indicative of fusion failure. The spine samples were scored independently by two different examiners. The segments were considered fused when both observers agreed such as bilateral fusion without any left or right motion was considered successful fusion; any motion detected between either transverse processes or facets or unilateral fusion was regarded as fusion failure $^{11)}$. Fusion between L4 and L5 was also radiographically
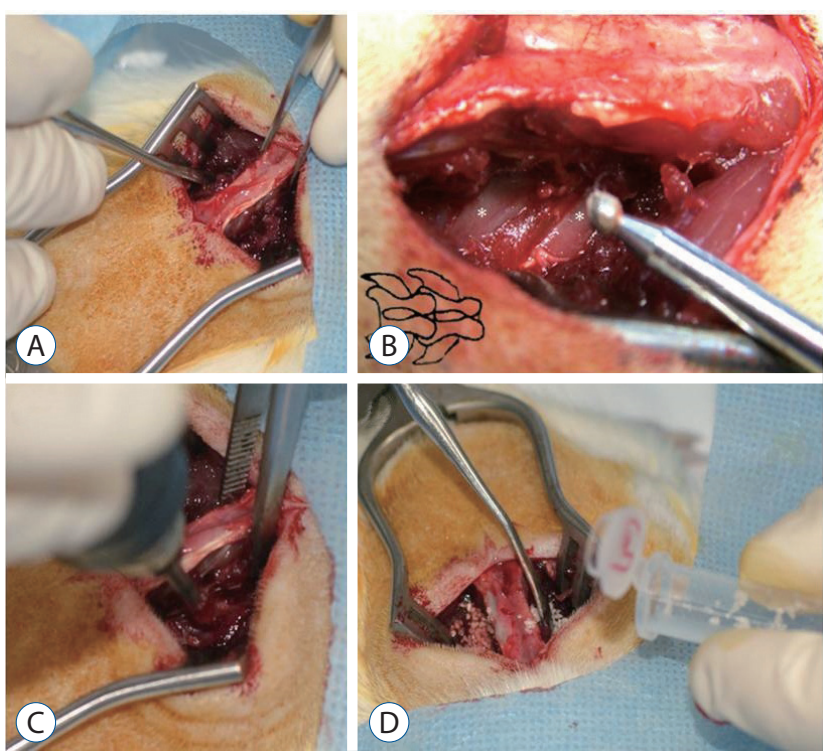

Fig. 2. Transverse processes were decorticated with a low-speed burr, and bone fusion material was implanted on each side. A : Midline paraspinal muscle splitting. $B$ : Asterisks indicate the transverse processes of $L 4$ and $L 5$. $\mathrm{C}$ : Decortication using a low-speed burr. D : Bone fusion material insertion. 
evaluated : fusion was considered to have occurred when there was clear evidence of new bone formation and osseous bridging with cortical continuity between the transverse process$\mathrm{es}^{11,22,30)}$. After radiographic evaluation, the sample spines were scanned subjected to high-resolution micro-CT (SkyScan-1072, Bruker, Kontich, Belgium) conducted at $90 \mathrm{kV}$ and $200 \mathrm{~mA}$. Visualization and data reconstruction were performed using a Ant ${ }^{\mathrm{TM}}$ and CT-Analyzer ${ }^{\mathrm{TM}}$ (SkyScan-1072, Bruker). The quality of formed fusion masses between transverse processes (L4 and L5) was also analyzed. Scanning of newly formed bone was initiated from the lower end plate level of the L4 vertebral body, and continued cranially at a resolution of $40 \mathrm{~mm}$ per voxel. Continuous trabecular and cortical bone connections between vertebrae and bone mass materials were considered indicative of fusion. Prominent bone mass without continuous connection was considered partial fusion.

After all radiographic examinations, spine samples (dissect- ed and formalin-fixed) were demineralized with 50\% formic acid and $10 \%$ sodium citrate. These were dehydrated in a graded ethanol series, and embedded in paraffin wax. The specimens were fixed in $10 \%$ formaldehyde solution, decalcified in formic acid for 48 hours, and embedded in paraffin blocks. Serial cross-sections $(5 \mu \mathrm{m})$, through largest defect diameters, were stained with hematoxylin-eosin (HE) and masson trichrome (MT) to reveal cellular reactions indicative of bone formation. Histologically, spine fusion was observed as the presence of bony trabeculae between transverse process$\mathrm{es}^{11,16,20)}$. alkaline phosphatase (ALP) staining was performed with a freshly prepared solution $(48 \mathrm{~mL})$ of Fast Blue RR1 containing $2 \mathrm{~mL}$ of Naphthol AS-MX phosphate and incubating samples in the dark for 1 hour $^{7)}$. ALP activity was quantified using an ALP detection kit (APF). The abilities of AB204 and rhBMP2 to trigger osteoblastic activity were compared by assessing integrated osteocalcin optical densities in each speci-

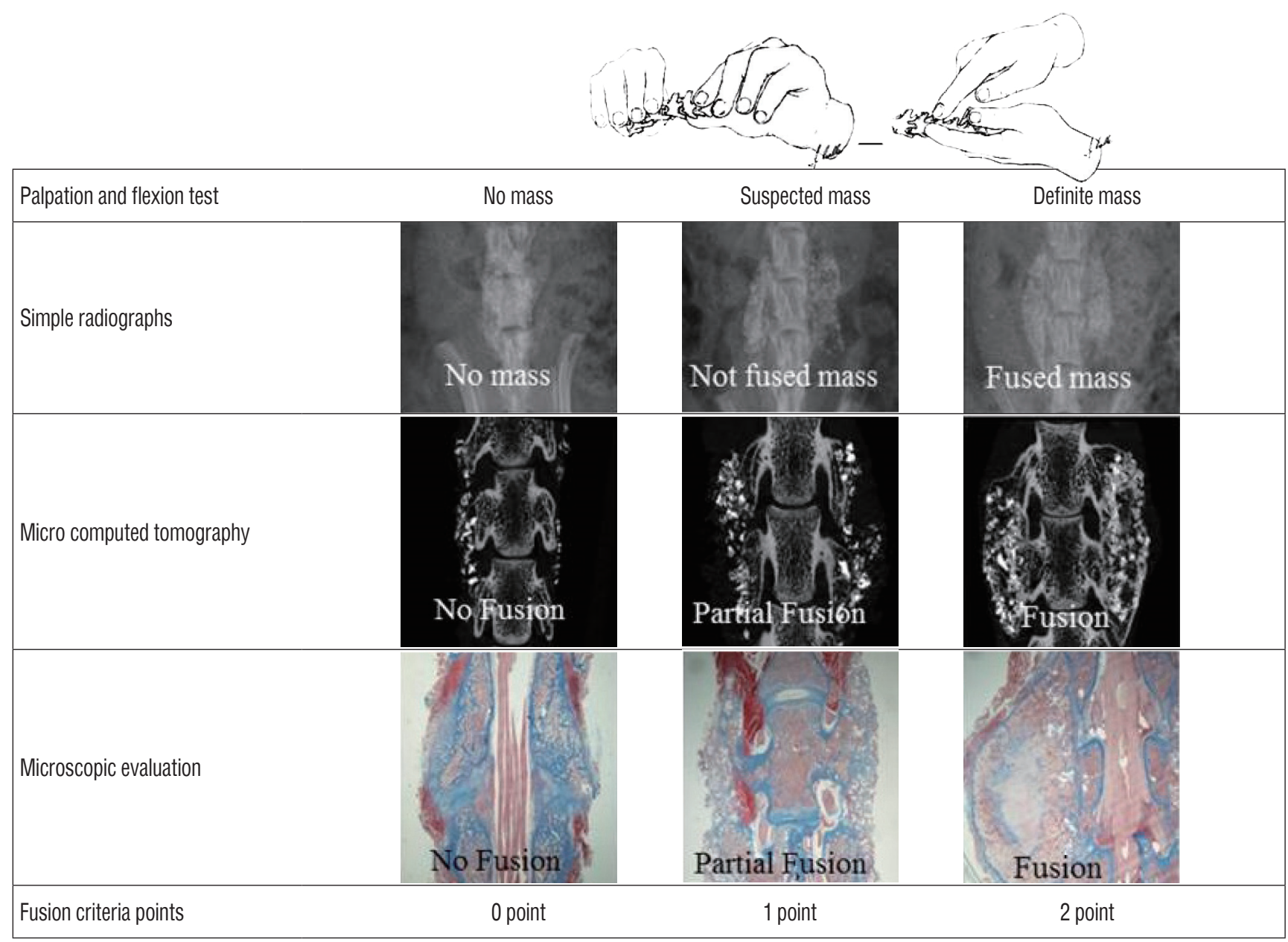

Fig. 3. Fusion scores were obtained using physical palpation, simple radiograph, micro-computed tomography, and immunohistochemistry. Fusion was scored as 0 (no fusion), 1 (partial fusion), or 2 (fusion) in each evaluation. 
men $^{14)}$. The IMAGEJ public domain image processing program was used to measure bone histomorphometric parameters of the fusion edges of implanted materials using the threshold function ${ }^{26)}$.

Quantitative data were analyzed using SPSS software ver- sion 12.0 (SPSS, Inc., Chicago, IL, USA) and results are reported as means \pm standard deviations. Spinal bone fusion properties were compared using Mann-Whitney U test. Statistical significance was accepted for $p<0.05$.
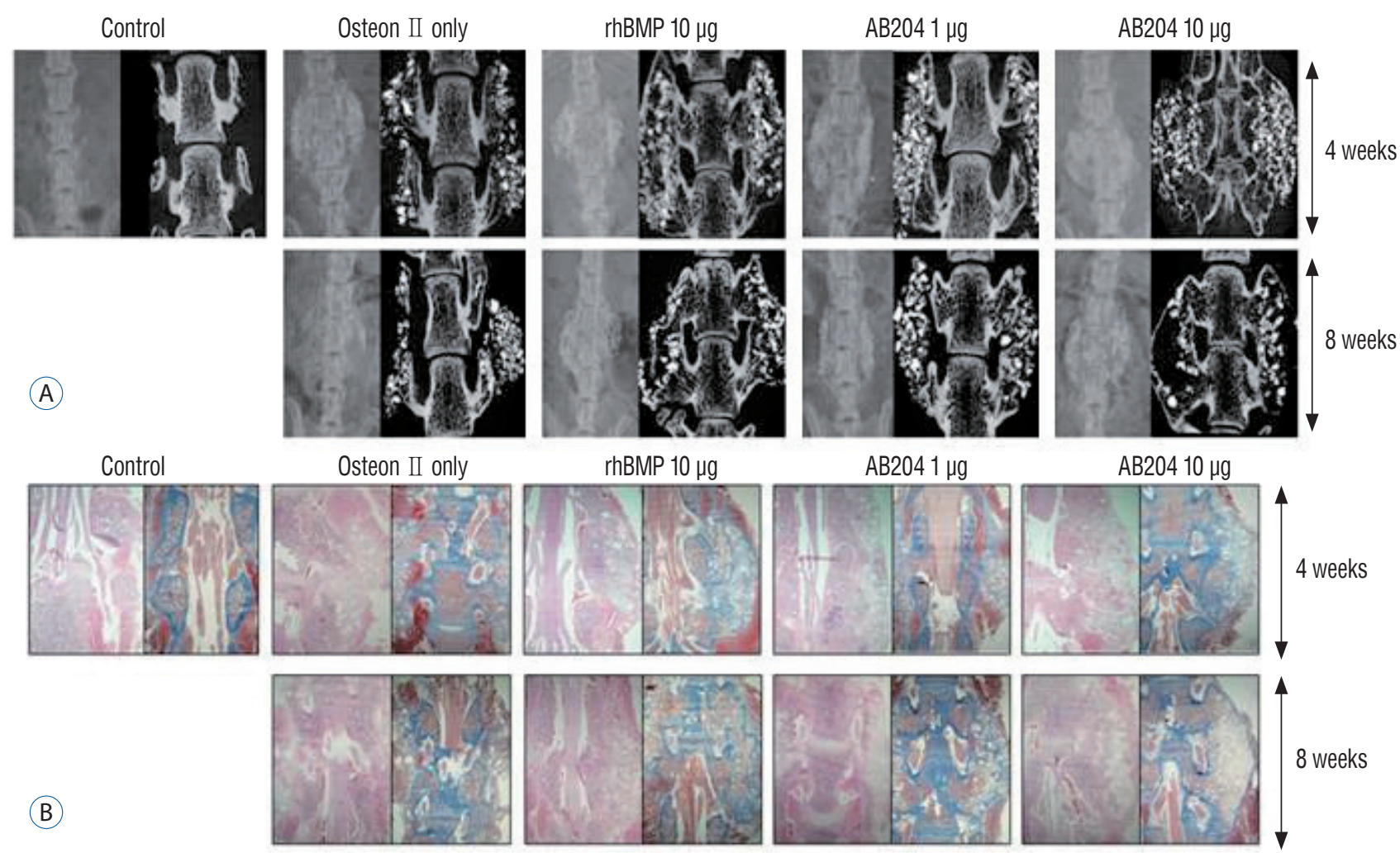

4 weeks
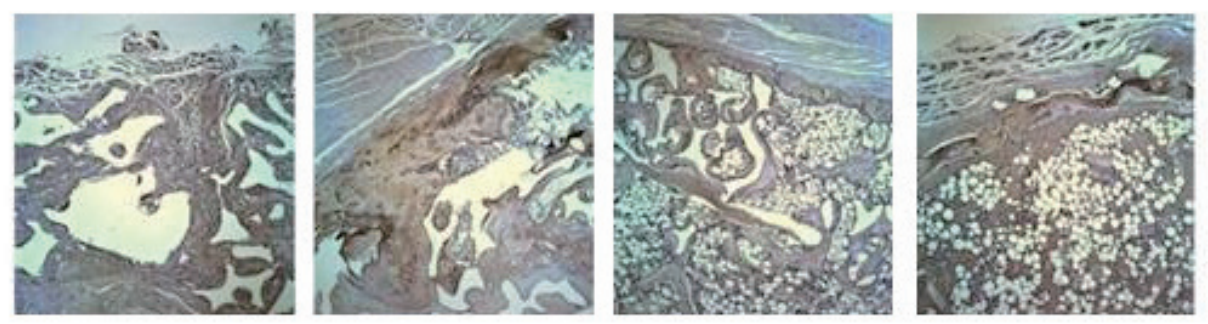

(C)

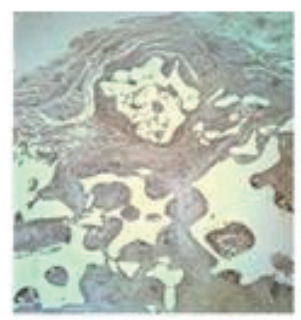

Osteon only

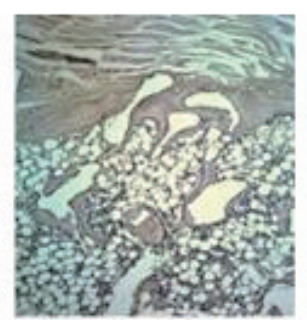

$\operatorname{rhBMP} 10 \mu \mathrm{g}$

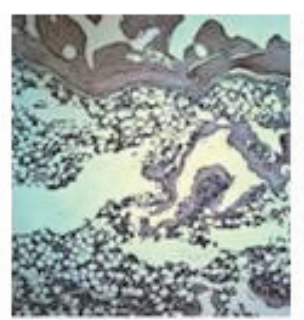

$\mathrm{AB} 2041 \mu \mathrm{g}$

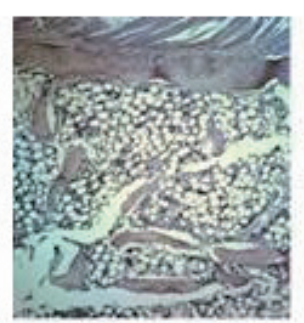

AB204 $10 \mu \mathrm{g}$

Fig. 4. Bone fusion results in the first study phas. A : Radiographic results. $B$ : Hematoxylin-eosin (HE) and Masson trichrome (MT) stain ( $\times 8)$. C : Alkaline phosphatase (ALP) stain ( $\times 200)$. rhBMP2, recombinant human bone morphogenetic protein, AB204: activin A/BMP2 chimera, CT: computed tomography. 


\section{RESULTS}

Rats were assigned to following five groups in the first study phase : sham (control), osteon only (only scaffold insertion), $10.0 \mu \mathrm{g}$ dosed rhBMP2 with osteon and $1.0 \mu \mathrm{g}$ or $10.0 \mu \mathrm{g}$ dosed AB204 with osteon groups. The spine of all rats in each group were manually palpated. Mean fusion scores with manual palpation at 4 weeks after surgery showed as follows; 0 in the sham group, 0 in the osteon only group, 1.5 in the $10.0 \mu \mathrm{g}$ dosed rhBMP2 with osteon group, 0.6 in the $1.0 \mu \mathrm{g}$ dosed AB204 with osteon group, and 1.9 in the $10.0 \mu \mathrm{g}$ dosed AB204 with osteon group. At 8 weeks after surgery, mean scores increased to 0.25 points in the osteon only group, 1.9 in the 10.0 $\mu \mathrm{g}$ dosed rhBMP2 with osteon group, 1.0 in the $1.0 \mu \mathrm{g}$ dosed AB204 with osteon group, and 1.9 in the $10.0 \mu \mathrm{g}$ dosed AB204 with osteon group. Radiologic results are shown in Fig. 4A. At 4 weeks after surgery, greater amount of radiological fusion was achieved in the $10.0 \mu \mathrm{g}$ dosed rhBMP2 and $10.0 \mu \mathrm{g}$ dosed AB204 groups than in the other three groups. In addition, fusion was denser at 8 weeks than at 4 weeks in all groups, except in the sham group.

$\mathrm{HE}$ and MT staining showed that bone fusion was greater in the $10.0 \mu \mathrm{g}$ dosed rhBMP2 or AB204 groups at 4 and 8 weeks than in the other groups (Fig. 4B). Of particular note, $10.0 \mu \mathrm{g}$ dosed AB204 and $10.0 \mu \mathrm{g}$ dosed rhBMP2 had similar fusion statuses as determined by microscopic examination. However, fusion in the $10.0 \mu \mathrm{g}$ dosed rhBMP2 group tended to be filled with fatty marrow within thin, eggshell-like cortical bone, whereas in the $10.0 \mu \mathrm{g}$ dosed AB204 group, marked increases in the amounts and thicknesses of trabecular bone were observed. At 4 weeks after surgery, ALP staining revealed higher amounts of osteocalcin in AB204 and rhBMP2 treated rats (Fig. 4C). At 4 weeks after surgery, integrated density of osteocalcin was significantly greater in the $10.0 \mu \mathrm{g}$ dosed rhBMP2 group than in the osteon only or $1.0 \mu \mathrm{g}$ dosed AB204 groups (Fig. 5A). However, no significant difference was observed between integrated density of osteocalcin in the $10.0 \mu \mathrm{g}$ dosed rhBMP2 and $10.0 \mu \mathrm{g}$ dosed AB204 groups. At 8 weeks, integrated density of osteocalcin decreased in all groups, although that was not prominent in the 1 and $10 \mu \mathrm{g}$ dosed AB204 groups. As a result, at 8 weeks, integrated density of osteocalcin became greater in the $10.0 \mu \mathrm{g}$ dosed AB204 group.

Total fusion scores for each group in the first phase of the study are summarized in Fig. 5B. Total fusion scores at 4 weeks after surgery were 0 points in the sham group, $2.0 \pm 1.4$ in the osteon only group, $7.2 \pm 1.3$ in the $10 \mu \mathrm{g}$ dosed rhBMP2 group, $4.6 \pm 2.5$ in the $1 \mu$ g dosed AB204 group, and $7.2 \pm 0.8$ in the $10 \mu \mathrm{g}$ dosed AB204 group. At 8 weeks, total fusion scores improved to $2.0 \pm 1.4$ in the osteon II only group, $7.2 \pm 0.84$ in the $10 \mu \mathrm{g}$ dosed rhBMP2 group, $4.4 \pm 3.8$ in the $1 \mu \mathrm{g}$ dosed AB204 group, and 7.4 \pm 1.1 in the $10 \mu \mathrm{g}$ dosed AB204 group. Fusion scores of the $10.0 \mu \mathrm{g}$ dosed rhBMP2 and AB204 groups showed no significant difference at 4 or 8 weeks, but fusion scores in the $1 \mu \mathrm{g}$ dosed AB204 group were significantly lower than those in the $10.0 \mu \mathrm{g}$ dosed rhBMP2 and $10.0 \mu \mathrm{g}$ dosed AB204 at 4 and 8 weeks.

In the second study phase, we investigated the effects of dosages in more detail at 4 and 8 weeks after surgery. Radiological and histological (HE, MT, and ALP stain) results at 8 weeks are summarized in Fig. 6. Bone fusion was greatly affected by rhBMP2 and AB204 in a dose-dependent manner. Integrated density of osteocalcin was significantly higher for AB204 at doses of 3.0 and $10.0 \mu \mathrm{g}$ than for rhBMP2 at same doses, respectively (Fig. 7A). Total fusion scores were $2.5 \pm 1.4$
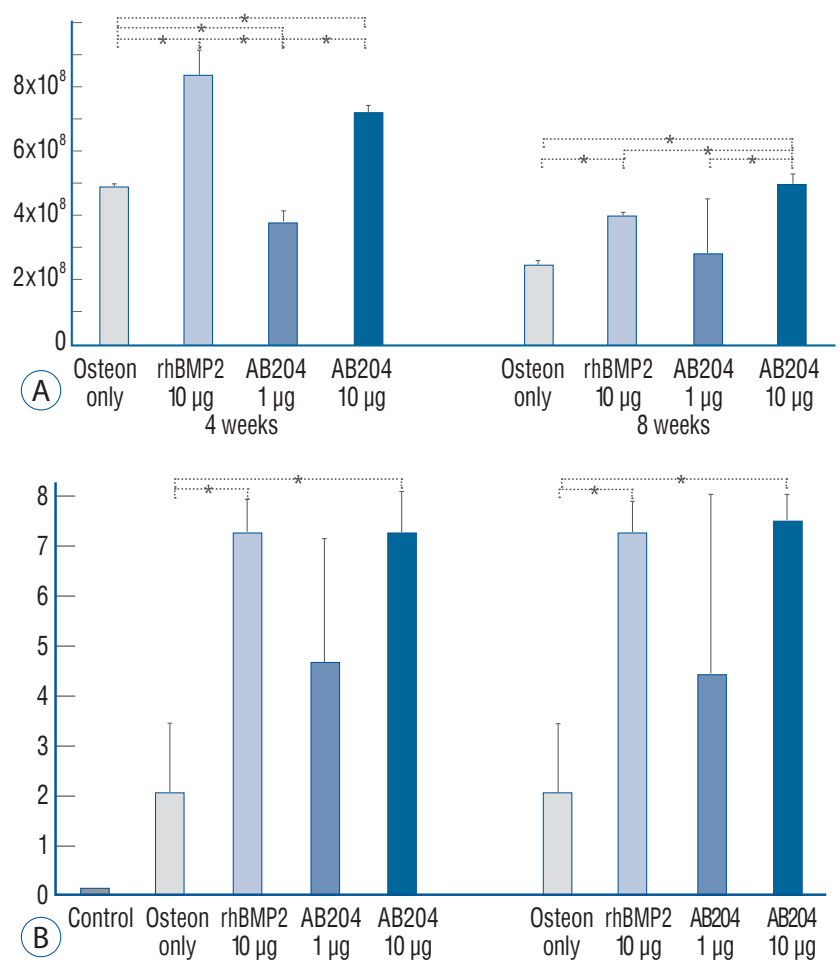

Fig. 5. Results in the first study phase. A : Integrated density of osteocalcin. B : Bone fusion score. *Significantly different $(p<0.001)$. rhBMP2, recombinant human bone morphogenetic protein, $A B 204$ : activin A/BMP2 chimera. 
$\operatorname{rhBMP} 3 \mu \mathrm{g}$
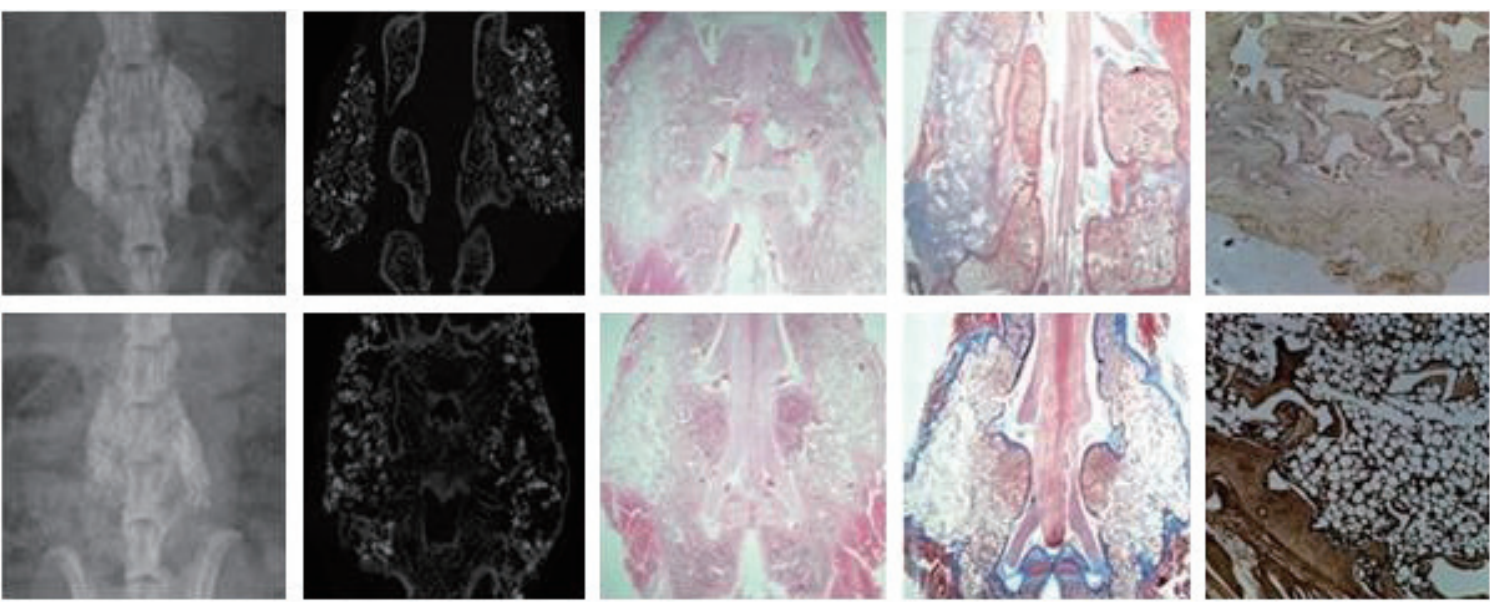

rhBMP $6 \mu \mathrm{g}$
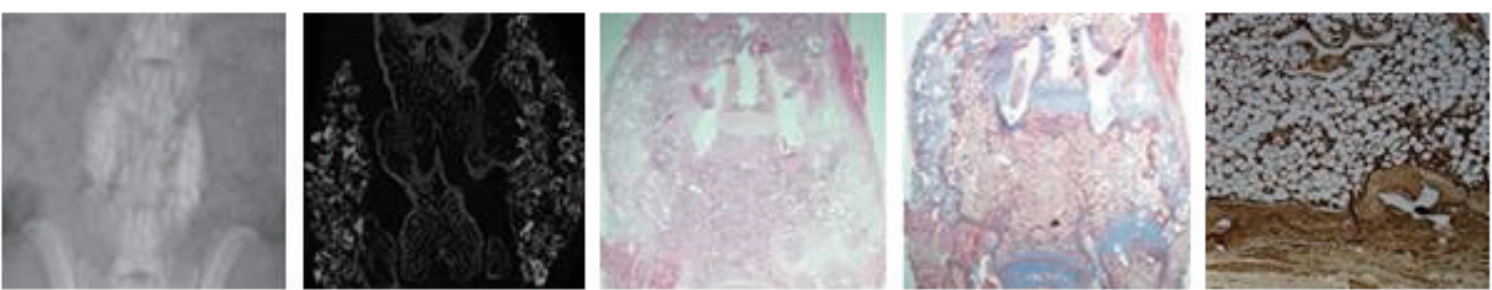

$\mathrm{AB} 2046 \mu \mathrm{g}$
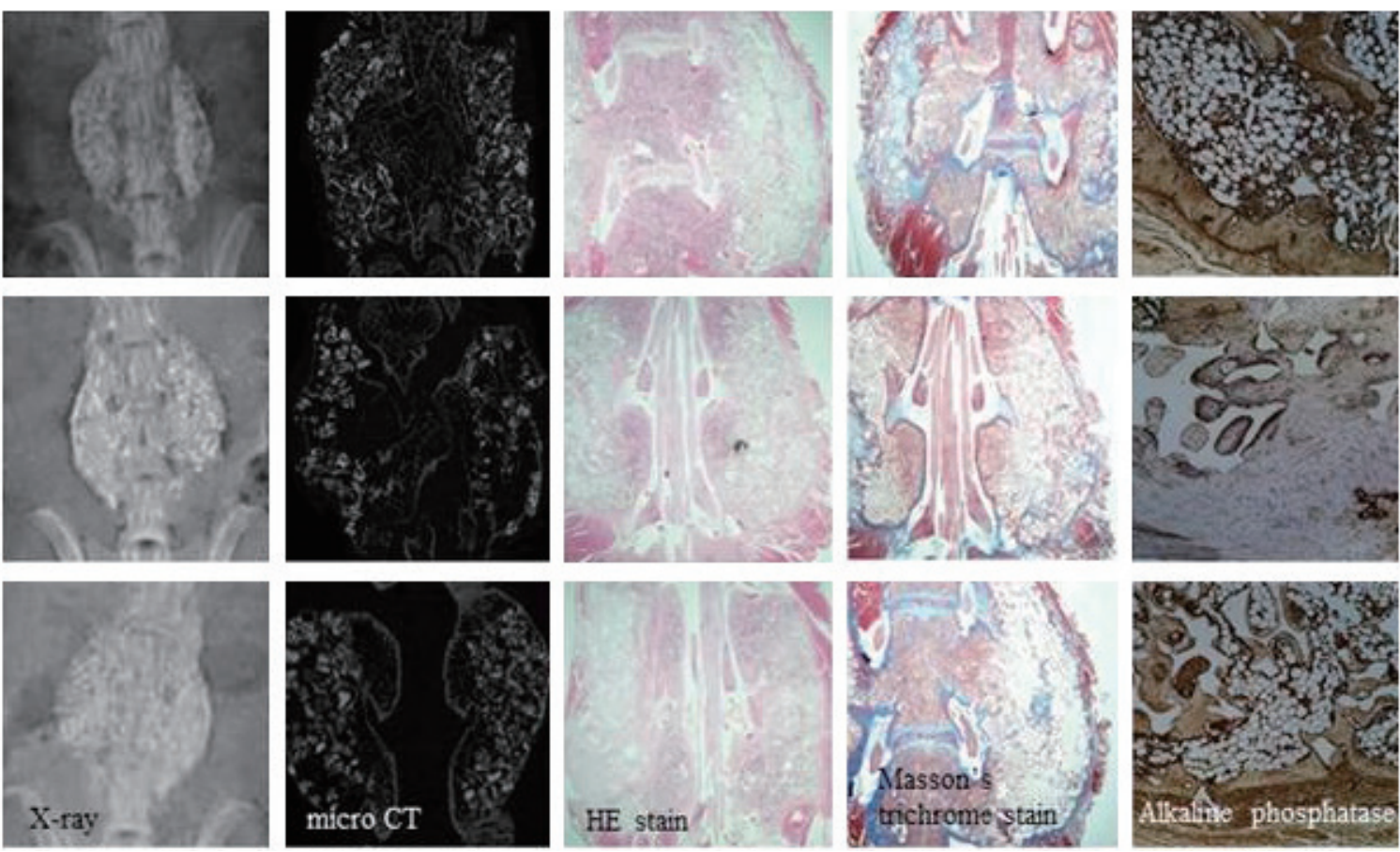

Fig. 6. The result of bone fusion on simple radiographs, micro- $C T$, and immunohistochemistry $(H E$, Masson trichrome $[\times 8]$, and alkaline phosphatase stain) in the second study phase. rhBMP2, recombinant human bone morphogenetic protein, AB204: activin A/BMP2 chimera, CT : computed tomography, $\mathrm{HE}$ : hematoxylin-eosin.

for $3 \mu \mathrm{g}$ dosed rhBMP2, $6.0 \pm 0.9$ for $3 \mu \mathrm{g}$ dosed AB204, $5.6 \pm 1.8$ for $6 \mu \mathrm{g}$ dosed rhBMP2, $6.4 \pm 1.8$ for $6 \mu \mathrm{g}$ dosed AB204, 7.0 \pm 0.8 for $10 \mu \mathrm{g}$ dosed rhBMP2, and $7.4 \pm 0.7$ for $10 \mu \mathrm{g}$ dosed AB204 (Fig. 7B). Only the scores for $3 \mu \mathrm{g}$ dosed rhBMP2 and AB204 were significantly different $(p<0.001)$. 


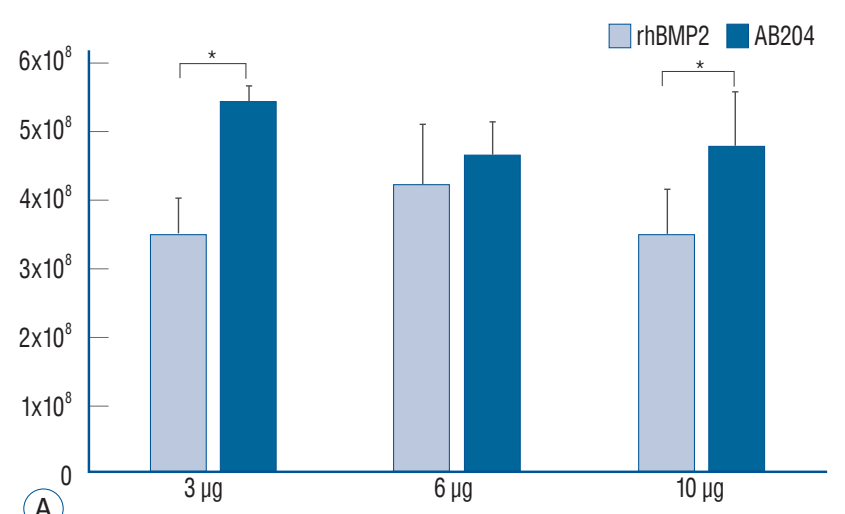

(A)

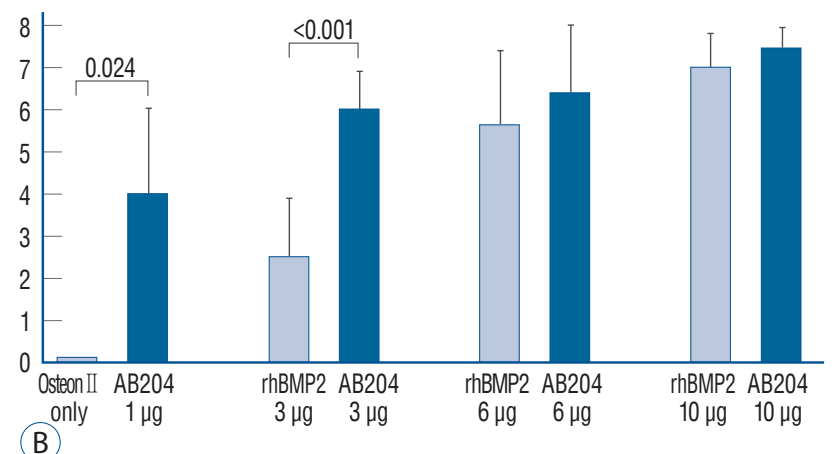
(B)

Fig. 7. Results in the second study phase. A : Integrated optical density of osteocalcin. B : Bone fusion score. *Significantly different $(p<0.001)$. rhBMP2, recombinant human bone morphogenetic protein, AB204: activin A/BMP2 chimera.

\section{DISCUSSION}

BMPs and activins belong to dimeric Transforming growth factor (TGF) $\beta$ superfamily ligands that make signals by binding and assembling both type I and type II transmembrane serine/threonine receptor kinases, as demonstrated in Fig. $8^{7)}$. As long as the ligand-induced receptors (type I and type II) were made, it constitutively makes type II receptor kinases phosphorylate, which activates type I receptors or activin-like kinases (Alks). Accordingly, Alks is phosphorylated and it activates cytoplasmic Smad proteins, which enters nuclei to get target gene transcribed ${ }^{7,14,26)}$. BMPs selectively bind with high affinity to type I receptors Alk1, Alk2, Alk3, and Alk6, and bind with low affinity the type II receptors ActRII, ActRIIb, and BMPRII. This leads to the group of receptor complexes that activate Smads 1,5 , and $8^{6,21)}$. However, activins bind the type II receptors ActRII and ActRIIb with very high affinity, and this leads to the secondary inducement of the type I receptors (Alk4 and Alk7) and to the activations of Smads 2 and 3 as well ${ }^{8,17,31)}$.

BMPs and activins had the structural differences which provided different properties. BMP2 adopts an extended rigid butterfly conformation ${ }^{4,10)}$, while activin possesses a level of

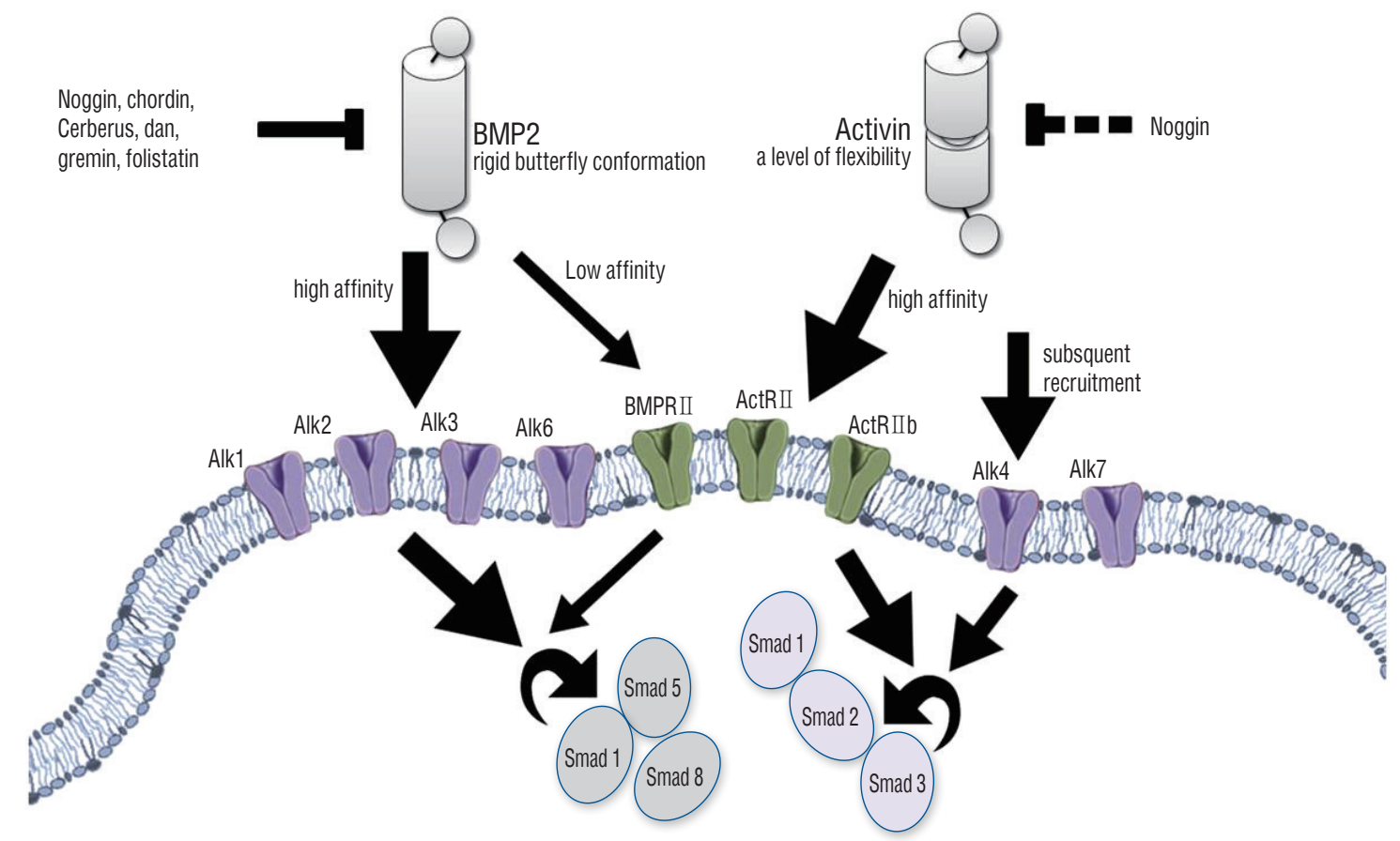

Fig. 8. BMP and activin signaling by binding and assembling type I and type II transmembrane serine/threonine receptor kinases. BMP : bone morphogenetic protein. 
flexibility which was not found in BMPs ${ }^{9,27)}$; activin has the ability to proceed a more closed conformation than other TGF $\beta$ superfamily members. This ternary complex structure of BMP2 bound to Alk3 (BMPRIa) and ActRII shows that the receptor extracellular domains not make physical contact with other. So, BMP2 binding to its receptors involves an element that mediates interactions between the receptor in cytoplasmic domains ${ }^{2}$. Both BMPs and activins unite the type II receptors of ActRII and ActRIIb with almost exactly the same spatial configuration ${ }^{2,10}$, chimeric ligands possessing the type I receptor biding on BMP2, and the high-affinity type II receptor on activin A could potentiate BMP2-like signaling properties $^{29)}$. In a previous study, the type II receptor epitope of BMP2 was replaced with that of activin A to create a chimeric ligand, which was named $\mathrm{AB} 204^{13}{ }^{13}$. This ligand utilizes the same Smads and signaling receptors as BMP2, but exhibits greater activity than BMP2, as observed in vitro signaling assays $^{11}$. These results suggest that AB204 could have superior biological effects (osteogenic and bone-healing properties) to those of BMP2. A previous in vitro and in vivo study demonstrated that AB204 had osteogenic and bone healing activities which exceeds the osteogenic and bone healing activities of $\mathrm{BMP} 2^{29)}$. We suspected that the crystal structure of AB204 facilitates this greater activity, as it possesses an amino acid residue derived from activin $\mathrm{A}$, which mutated to the corresponding BMP2 residue, resulted in a version of AB204 with increased affinity for the type I receptor BMPRla and enhanced osteogenic potency in vitro.

Recent studies showed that activin A/BMP2 chimeras have replaced as role of BMP2 substitutes with higher osteogenic potentials ${ }^{1,29)}$. In a present study, the bone fusion properties between AB204 and rhBMP2 were similar at doses of 6.0 and $10.0 \mu \mathrm{g}$, but the bone fusion properties of AB204 at $3.0 \mu \mathrm{g}$ dose were superior to those of $3.0 \mu \mathrm{g}$ dosed rhBMP2. In addition, AB204 showed more prolonged osteoblastic activity than rhBMP2, according to our results on integrated density of osteocalcin. These results may be resulted from the nature of activin A, which displays a high level of plasticity and is not respond to the BMP2 antagonist Noggin ${ }^{10,29)}$. Nevertheless, the spinal bone properties of AB204 at lower did not agree with the results of a completely cured tibial and calvarial defects in mice with $1 / 10$ dosage compared to rhBMP $2^{29)}$. In the present study, AB204 showed similar or better bone fusion than rhBMP2 at same concentrations. We suspect that various factors related to the mobility of anatomical structures and surgical preparation of fusion materials may have led to this discrepancy.

Generally, high doses of rhBMP2 are required to achieve therapeutic effects, but these doses can result in side effects that limit medical applications. In particular, soft tissue swelling, one of the most common rhBMP2 complications, can lead to dysphagia, an ailment that has been reported to be more frequent and severe in patients administered rhBMP2 during anterior cervical discectomy and fusion ${ }^{1}$. On the other hand, AB204 is proven to offer the ability of effective bone fusion at lower dose than rhBMP2. Therefore, even if the side effects are inherently associated with activation of the BMP2 signaling pathway, temporal and spatial dynamics related to a lower dosage of AB204 would result in fewer unwanted side effects.

There are several limitations in this study. First, numbers of each group are small to demonstrate a powerful statistical significance. However, significance with non-parametrical statistical method was shown with minimal sacrifice of experimental animals. Second, because this study was not conducted with a blind manner, a possibility of bias cannot be excluded perfectly. Lastly, more predominant bone fusion property of AB204 than rhBMP2 with a lower dosage does not mean less frequent occurrence of complication during bone fusion necessarily. Further study to reveal the direct mechanism of complication with both rhBMP2 and AB204 is required.

\section{CONCLUSION}

AB204 is proven to offer the ability of effective bone fusion at lower dose than rhBMP2 in a rat. We suggest that AB204 chimeras can be more potent materials for treating spinal bone fusion than rhBMP2 and it can be one of substitutes with rhBMP2 in spinal fusion.

\section{CONFLICTS OF INTEREST}

No potential conflict of interest relevant to this article was reported.

\section{- Acknowledgements}

This study was supported by a grant of the Korea Health Technology R\&D Project through the Korea Health Industry De- 
velopment Insitute (KHIDI), funded by the Ministry of Health \& Welfare, Republic of Korea (grant number : HI12C0006). And this work was supported by Inha University Research Grant as well.

\section{References}

1. Allendorph GP, Read JD, Kawakami Y, Kelber JA, Isaacs MJ, Choe S : Designer TGF $\beta$ superfamily ligands with diversified functionality. PLoS One 6 : e26402, 2011

2. Allendorph GP, Vale WW, Choe $S$ : Structure of the ternary signaling complex of a TGF- $\beta$ superfamily member. Proc Natl Acad Sci U S A $103: 7643-7648,2006$

3. Bhatt RA, Rozental TD : Bone graft substitutes. Hand Clin 28 : 457468, 2012

4. Brown MA, Zhao Q, Baker KA, Naik C, Chen C, Pukac L, et al. : Crystal structure of BMP-9 and functional interactions with pro-region and receptors. J Biol Chem 280 : 25111-25118, 2005

5. Campana V, Milano G, Pagano E, Barba M, Cicione C, Salonna G, et al. : Bone substitutes in orthopaedic surgery: From basic science to clinical practice. J Mater Sci Mater Med 25 : 2445-2461, 2014

6. Chen Y, Bhushan A, Vale W : Smad8 mediates the signaling of the ALK2 [corrected] receptor serine kinase. Proc Natl Acad Sci U S A 94 : 12938-12943, 1997

7. Derynck R, Miyazono K : The tgf-[beta] family. CSHL Press 50 : 29-43, 2008

8. Gray PC, Greenwald J, Blount AL, Kunitake KS, Donaldson CJ, Choe S, et al. : Identification of a binding site on the type ii activin receptor for activin and inhibin. J Biol Chem 275 : 3206-3212, 2000

9. Greenwald J, Groppe J, Gray P, Wiater E, Kwiatkowski W, Vale W, et al. : The BMP7/actrii extracellular domain complex provides new insights into the cooperative nature of receptor assembly. Mol Cell 11 : 605-617, 2003

10. Greenwald J, Vega ME, Allendorph GP, Fischer WH, Vale W, Choe S : A flexible activin explains the membrane-dependent cooperative assembly of TGF- $\beta$ family receptors. Mol Cell 15 : 485-489, 2004

11. Han X, Zhang W, Gu J, Zhao H, Ni L, Han J, et al. : Accelerated posterolateral spinal fusion by collagen scaffolds modified with engineered collagen-binding human bone morphogenetic protein-2 in rats. PLoS One 9 : e98480, 2014

12. Joseph $V$, Rampersaud YR : Heterotopic bone formation with the use of rhBMP2 in posterior minimal access interbody fusion: a CT analysis. Spine (Phila Pa 1976) 32 : 2885-2890, 2007

13. Kamiya N, Ye L, Kobayashi T, Mochida Y, Yamauchi M, Kronenberg HM, et al. : BMP signaling negatively regulates bone mass through sclerostin by inhibiting the canonical Wnt pathway. Development 135 : 38013811, 2008

14. Koenig BB, Cook JS, Wolsing DH, Ting J, Tiesman JP, Correa PE, et al. :
Characterization and cloning of a receptor for BMP-2 and BMP-4 from NIH 3 T3 cells. Mol Cell Biol 14 : 5961-5974, 1994

15. Latzman JM, Kong L, Liu C, Samadani U : Administration of human recombinant bone morphogenetic protein-2 for spine fusion may be associated with transient postoperative renal insufficiency. Spine (Phila Pa 1976) 35 : E231-E237, 2010

16. Lu J, Bhargav D, Wei AQ, Diwan A : Posterolateral intertransverse spinal fusion possible in osteoporotic rats with BMP-7 in a higher dose delivered on a composite carrier. Spine (Phila Pa 1976) 33 : 242-249, 2008

17. MassaguéJ, Weis-Garcia F : Serine/threonine kinase receptors: mediators of transforming growth factor beta family signals. Cancer Surv 27 : 41-64, 1996

18. Mesfin A, Buchowski JM, Zebala LP, Bakhsh WR, Aronson AB, Fogelson $J$, et al. : High-dose rhBMP-2 for adults: major and minor complications: a study of 502 spine cases. J Bone Joint Surg Am 95 : 1546-1553, 2013

19. Miron R, Zhang $Y$ : Osteoinduction: a review of old concepts with new standards. J Dent Res 91 : 736-744, 2012

20. Miyazaki M, Morishita Y, He W, Hu M, Sintuu C, Hymanson HJ, et al. : A porcine collagen-derived matrix as a carrier for recombinant human bone morphogenetic protein-2 enhances spinal fusion in rats. Spine J 9 : 22 30, 2009

21. Nishimura R, Kato Y, Chen D, Harris SE, Mundy GR, Yoneda T : Smad5 and DPC4 are key molecules in mediating BMP-2-induced osteoblastic differentiation of the pluripotent mesenchymal precursor cell line $\mathrm{C} 2 \mathrm{C} 12$. J Biol Chem 273 : 1872-1879, 1998

22. Park BH, Song KJ, Yoon SJ, Park HS, Jang KY, Zhou L, et al. : Acceleration of spinal fusion using COMP-angiopoietin 1 with allografting in a rat model. Bone 49 : 447-454, 2011

23. Pimenta L, Marchi L, Oliveira L, Coutinho E, Amaral R : A prospective, randomized, controlled trial comparing radiographic and clinical outcomes between stand-alone lateral interbody lumbar fusion with either silicate calcium phosphate or rh-BMP2. J Neurol Surg A Cent Eur Neurosurg $74:$ 343-350, 2013

24. Pryor LS, Gage E, Langevin C-J, Herrera F, Breithaupt $A D$, Gordon $C R$, et al. : Review of bone substitutes. Craniomaxillofac Trauma Reconstr 2 : 151-160, 2009

25. Schlickewei $W$, Schlickewei $C$ : The use of bone substitutes in the treatment of bone defects-the clinical view and history. Macromol Symp $253: 10-23,2007$

26. ten Dijke P, Franzén $P$, Yamashita $H$, Ichijo $H$, Heldin $C H$, Miyazono $\mathrm{K}$ : Serine/threonine kinase receptors. Prog Growth Factor Res 5 : 55 72, 1994

27. Thompson TB, Woodruff TK, Jardetzky TS : Structures of an ActRiii: activin A complex reveal a novel binding mode for TGF- $\beta$ ligand: receptor interactions. EMBO J 22 : 1555-1566, 2003

28. Wang JC, Kanim LE, Yoo S, Campbell PA, Berk AJ, Lieberman JR : Effect of regional gene therapy with bone morphogenetic protein-2-producing bone marrow cells on spinal fusion in rats. J Bone Joint Surg Am 85-A : 905-911, 2003 
Bone Fusion Properties of AB204 | Ryu D, et al.

29. Yoon BH, Esquivies L, Ahn C, Gray PC, Ye Sk, Kwiatkowski W, et al. : An activin A/BMP2 chimera, AB204, displays bone-healing properties superior to those of BMP2. J Bone Miner Res 29 : 1950-1959, 2014

30. Zhu W, Rawlins BA, Boachie-Adjei O, Myers ER, Arimizu J, Choi E, et al. : Combined bone morphogenetic protein-2 and -7 gene transfer enhances osteoblastic differentiation and spine fusion in a rodent model. J Bone Miner Res 19 : 2021-2032, 2004

31. Zimmerman C, Mathews L : Activin receptors: Cellular signalling by receptor serine kinases. Macromol Symp 253 : 10-23, 2007 